\title{
Current patterns of collaboration in published neurology research
}

\section{Author collaboration in neurological research}

\author{
Yassar Alamri ${ }^{1,2,3}$ (D)
}

Received: 15 January 2017 / Accepted: 20 February 2017 /Published online: 22 March 2017

(C) European Association for Predictive, Preventive and Personalised Medicine (EPMA) 2017

Keywords Collaboration · Medical research · Neurology · Solitary research $\cdot$ Open access $\cdot$ Politics

\section{Introduction}

Data generated from single centres, whilst convenient to collect, analyse and fund, may be subject to critical biases [1]. Much of the literature in the field of interventional neuroradiology, for example, is said to be based upon single centre experience or multi-centre retrospective analyses [2].

Not only is international multi-centre collaborative research more likely to yield more robust and generalisable data [3], but it also is more likely to yield higher-echelon evidence base, and thus directly influencing patient care [4]. This, in addition, can help guide the allocation of funding and human resources governing agencies and non-governmental organisations.

Although the benefits of high-quality single centre and retrospective data ought not to be trivialised [1], the importance of collaborative research is being increasingly recognised in the literature [5]. Therefore, the aim of this study was to examine the patterns of collaboration in research studies published in several neurology journals.

Yassar Alamri

Yassar.alamri@nzbri.org

1 New Zealand Brain Research Institute, 66 Stewart Street, Central Christchurch 8011, New Zealand

2 Christchurch School of Medicine, University of Otago, Christchurch, New Zealand

3 Department of Medicine, University of Otago, Christchurch, New Zealand

\section{Methods}

Study setting

All in press manuscripts accepted for publication in one of seven of the most highly cited neurology journals were reviewed over a two-month period (01 August 2016 to 30 September 2016). The included journals were Acta Neuropathologica, Annals of Neurology, Brain, JAMA Neurology, Lancet Neurology, Nature Reviews Neurology and Neurology.

\section{Research types}

Non-research content, such as editorials and commentaries, was excluded. The study design was specified as follows: systematic reviews and meta-analyses, randomised controlled trials, prospective series ( $\geq 10$ patients), retrospective series ( $\geq 10$ patients), case series (2-9 patients), case reports and laboratory studies (animal and in vitro studies).

\section{Author affiliations}

Each author's country was recorded. All departments or groups within a given institution were categorised as one. Therefore, all affiliations from different departments within the same university were counted as a single centre.

\section{Results}

\section{General results}

A total of 204 manuscripts were reviewed; of these, 107 research articles were included in the study. The number 
of in press research articles varied greatly amongst journals and generally ranged from 5-44 manuscripts. The median number of authors per article was 8 (range 1-33).

\section{Types of included studies}

Figure 1 shows the number of research articles stratified by study design. A sizeable proportion of the studies (39.3\%) was of prospective design.

\section{Institutional collaboration}

A mean of $4.3( \pm 3.4)$ institutions were represented by each study. Of the included studies, 61 (57\%) were single-centre studies. Just over half of the studies involved a collaboration of three or fewer institutions (56.1\%). Institution collaboration was significantly less for systematic reviews/meta-analyses $(1.7 \pm 1.2)$ than for original research articles $(3.5 \pm 3.1$; $p=0.004$ ) (Fig. 2).

International collaboration resulted in 45 (42.1\%) publications. Details of the most proliferative countries are shown in Table 1. The median number of authors per single-institution article (6.5; range 1-33) was significantly lower than that of articles resulting from international collaboration (12; range $2-23 ; p=0.03)$.

\section{Discussion}

The present study investigated the patterns of collaboration in research studies published in high-impact neurology journals. Overall, over a third of the studies were prospective in design. Authors from different countries collaborated to produce $42.1 \%$ of the articles.

Whilst the results are encouraging, they are likely to be positively skewed. Articles published in such high-impact journals are often the highest on the quality spectrum in

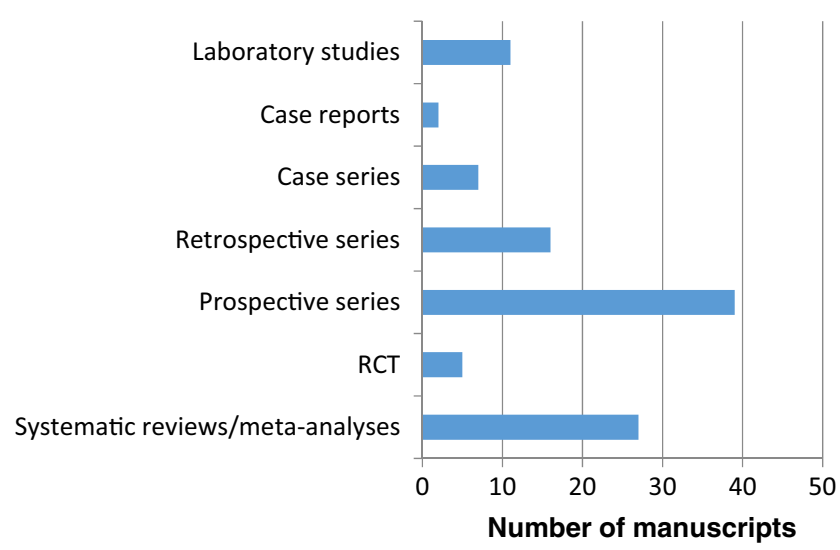

Fig. 1 Types of studies

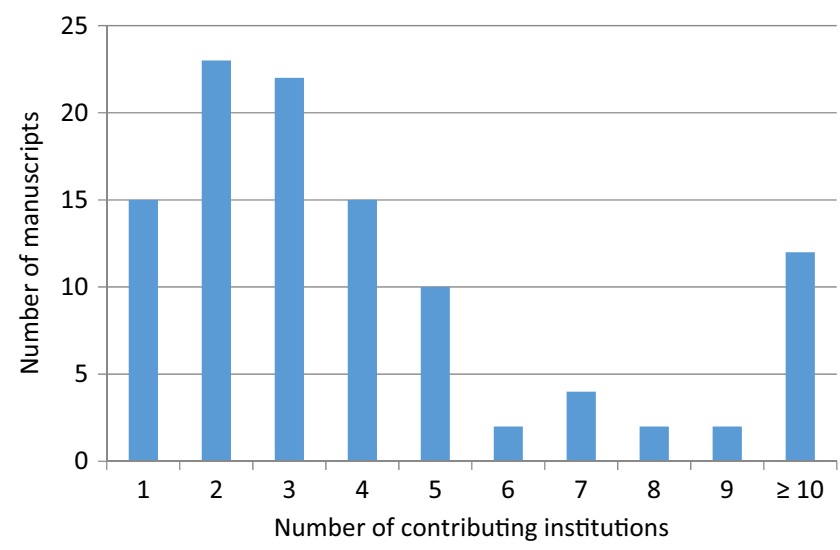

Fig. 2 Number of manuscripts based on the number of contributing institutions

terms of study design and power and number of study sites [4]. For example, examination of articles published in a mid-tier interventional neuroradiology journal over a period of 12 months revealed a proportion of prospective studies (3.9\%) [2] that is ten times less than findings in the current study (39.3\%).

Authors from the USA published the most articles (both solitary and collaborative). It would be intriguing to re-examine the observed patterns in light of the ongoing political unrest in the USA (i.e. presidential elections) and the UK ( i.e. post-Brexit) given the documented effect on the political milieu on medical research $[6,7]$.

With the recent emergence of open-access journals, it is worth commenting on how it may affect the dissemination of collaborative research findings. An increasing proportion of funders (e.g., the National Institutes of Health and Wellcome Trust) are enforcing publishing under open access [8]. For collaborative research, this may translate into a higher number of articles in open-access journals. For solitary research, on the other hand, publishing in openaccess journals may in fact attract local and international collaborators $[8,9]$; thus, a virtuous cycle of enhanced collaboration and increased readability of research findings ensues.

Several weaknesses inherent to this type of study ought to be mentioned. Most of the chosen journals originate from the USA or UK; this could have skewed the institutional representation to favour US- or UK-authored articles in spite of the fact that the journals accept submissions from any scientific institution. Additionally, the study period was limited, although the number of reviewed articles was sufficiently substantial to extrapolate meaningful results. Future studies of longer durations and a wider array of journals ought to be conducted in order to corroborate our findings. 
Table 1 Details of the most proliferative countries

\begin{tabular}{|c|c|c|c|c|}
\hline $\begin{array}{l}\text { Most } \\
\text { proliferative } \\
\text { countries }\end{array}$ & $\begin{array}{l}\text { Number of } \\
\text { solitary } \\
\text { contributions } \\
(\%)\end{array}$ & $\begin{array}{l}\text { Number of } \\
\text { collaborative } \\
\text { contributions }(\%)\end{array}$ & $\begin{array}{l}\text { Total number of } \\
\text { collaborating } \\
\text { countries }\end{array}$ & $\begin{array}{l}\text { Most common collaborating } \\
\text { countries }(n)\end{array}$ \\
\hline USA & $31(29 \%)$ & $22(20.6 \%)$ & 22 & $\begin{array}{l}\text { Canada (6), UK (5), Germany } \\
\text { (4), Netherlands (4), } \\
\text { Australia (3). }\end{array}$ \\
\hline UK & $6(5.6 \%)$ & $15(14 \%)$ & 21 & $\begin{array}{l}\text { USA (5), Germany (4), } \\
\text { Canada (3), Sweden (3). }\end{array}$ \\
\hline Germany & $4(3.7 \%)$ & $11(10.3 \%)$ & 16 & $\begin{array}{l}\text { UK (4), USA (4), Australia } \\
\text { (3), Switzerland (3). }\end{array}$ \\
\hline Canada & $2(1.9 \%)$ & $9(8.4 \%)$ & 9 & USA (6), UK (3). \\
\hline
\end{tabular}

UK United Kingdom; USA United States of America

\section{Compliance with ethical standards}

Conflict of interest The author declares that he has no conflict of interest.

\section{References}

1. Glasziou P, Vandenbroucke JP, Chalmers I. Assessing the quality of research. BMJ. 2004;328(7430):39-41.

2. Fargen KM, Mocco J, Spiotta AM, Rai A, Hirsch JA. A pilot study of neurointerventional research level of evidence and collaboration. J Neurointerv Surg. 2016. doi:10.1136/neurintsurg-2016-012504.
3. Tonini C, Beghi E, Telaro E, Candelise L. The Cochrane collaboration in neurology: acquisitions, research, and new initiatives. Neuroepidemiology. 2001;20(2):153-9.

4. Jacobson DA, Bhanot K, Yarascavitch B, Chuback J, Rosenbloom E, Bhandari M. Levels of evidence: a comparison between top medical journals and general pediatric journals. BMC Pediatr. 2015;15:3.

5. Freeman RB, Huang W. Collaboration: Strength in diversity. Nature. 2014;513(7518):305.

6. Bifulco M. Politics and Research: a desirable and essential dialogue. Transl Med UniSa. 2015;11:1-2.

7. Yang H, Flower RJ, Huang X. Fellowships: Brexit threatens China collaboration. Nature. 2016;537(7619):167.

8. Spires-Jones TL, Poirazi P, Grubb MS. Opening up: open access publishing, data sharing, and how they can influence your neuroscience career. Eur J Neurosci. 2016;43(11):1413-9.

9. Bjork BC. Open access to scientific articles: a review of benefits and challenges. Intern Emerg Med. 2017;12(2):247-53. 